\title{
Sex-specific survival benefit in early skin melanoma based on 8th AJCC edition: an analysis of data from the Surveillance, Epidemiology, and End Results (SEER) database
}

\author{
Ran Mo ${ }^{1,2 \#}$, Chen Chen ${ }^{3 \#}$, Yanan Jiang ${ }^{2 \#}$, Zhouji Ma ${ }^{1}$, Xueyong Meng ${ }^{2}$, Qian Tan ${ }^{1,2}$ \\ ${ }^{1}$ Department of Burns \& Plastic Surgery, Nanjing Drum Tower Hospital Clinical College of Nanjing Medical University, Nanjing, China; \\ ${ }^{2}$ Department of Burns \& Plastic Surgery, Nanjing Drum Tower Hospital, the Affiliated Hospital of Medical School of Nanjing University, Nanjing, \\ China; ${ }^{3}$ Department of Nutrition, Nanjing Drum Tower Hospital, the Affiliated Hospital of Medical School of Nanjing University, Nanjing, China \\ Contributions: (I) Conception and design: R Mo; (II) Administrative support: Q Tan; (III) Provision of study materials or patients: R Mo; (IV) \\ Collection and assembly of data: R Mo, C Chen; (V) Data analysis and interpretation: R Mo, C Chen, Y Jiang; (VI) Manuscript writing: All authors; \\ (VII) Final approval of manuscript: All authors. \\ \#These authors contribute equal to this article. \\ Correspondence to: Qian Tan. Department of Burn \& Plastic Surgery, Nanjing Drum Tower Hospital Clinical College of Nanjing Medical University; \\ Department of Burn \& Plastic Surgery, Nanjing Drum Tower Hospital, the Affiliated Hospital of Medical School of Nanjing University. 321 \\ Zhongshan Road, Nanjing 210008, China. Email: smmutanqian@sina.com.
}

\begin{abstract}
Background: Females have been found to have a survival benefit over males in past studies. However, in early melanoma patients, this benefit occurred in only those aged $>60$ years. The 8 th edition of the American Joint Committee on Cancer (AJCC) readjusted the melanoma staging system, specifically stage I. This study aims to verify whether the sex-specific benefit in females exists in different age groups according to the 8th edition of the staging system.

Methods: We collected the data of individuals diagnosed with skin melanoma between 2004 and 2015 from the Surveillance, Epidemiology, and End Results (SEER) database. Based on the 8th edition of the melanoma staging system, patients diagnosed with pathological stage T1a-T3a, N0 and M0 melanoma were enrolled.

Results: A total of 115,576 patients, including 62,938 male patients and 52,638 female patients, were enrolled in this study. The survival rates of males and females in each stage from IA-IIA were significantly different $(\mathrm{P}<0.001)$. In further analyses of each age group, it was found that the proportions of patients with stages IA, IB and IIA were significantly different in each age group. Cox analysis showed that females with stage IA in all age groups benefited significantly, but those in stage IB benefited only when they were aged $>60$ years. In stage IIA patients, there were significant differences between the $<50$ and $61-70$ years age groups.
\end{abstract}

Conclusions: Based on data from the SEER database, we found that according to the 8th edition of the AJCC melanoma staging system, females had a higher survival rate than males, and this difference was significant in all age groups in the stage IA group but fluctuated with age in the stage IB and IIA groups.

Keywords: Melanoma; Surveillance, Epidemiology, and End Results (SEER); TNM stage; female; sex

Submitted May 10, 2020. Accepted for publication Sep 25, 2020.

doi: $10.21037 / \mathrm{atm}-20-3845$

View this article at: http://dx.doi.org/10.21037/atm-20-3845

(c) Annals of Translational Medicine. All rights reserved. 


\section{Introduction}

In October 2016, the 8th edition of the melanoma staging system was published, and the system was officially implemented on January 1, 2018 (1). In this edition, an important adjustment was made, which refined the T1 stage; for the first time, the new system considers a thickness of $0.8 \mathrm{~mm}$ as a separation indicator (Table 1). Previous American Joint Committee on Cancer (AJCC) staging manuals have recommended that the melanoma tumour thickness should be accurate to $0.01 \mathrm{~mm}(2,3)$. However, considering the accuracy of measurement, especially the thickness of tumours in paraffin sections, is difficult to obtain an accuracy of $0.01 \mathrm{~mm}$. In the 8 th edition, this accuracy value was eliminated and adjusted to $0.1 \mathrm{~mm}$. Tumours with thicknesses of $0.75-0.84 \mathrm{~mm}$ are collectively considered $0.8 \mathrm{~mm}$, and tumours with thicknesses of 0.95-1.04 $\mathrm{mm}$ are considered $1.0 \mathrm{~mm}$. Furthermore, the definition of T1 has also been adjusted. Although the mitotic rate is still considered to be an independent risk factor that may affect prognosis $(4,5)$, it was abandoned as an indicator; in the 7th edition, it was used to differentiate $\mathrm{T} 1 \mathrm{a}$ and $\mathrm{T} 1 \mathrm{~b}$. Ulceration was re-added as a criterion for the T1 stage. These three changes have resulted in substantial changes to the classification of the T1 stage.

Another major change is the staging system. In previous editions, in N0M0 cases, T1b + T2a were regarded as stage IB, and T1a was regarded as stage IA $(2,3)$. In the 8 th edition, the stage representing early melanoma was adjusted, $\mathrm{T} 1 \mathrm{a}+\mathrm{T} 1 \mathrm{~b}$ were collectively included in stage IA, and T2a was separately treated as stage IB (Figure 1). This change not only applies to melanoma but also applies to other tumours, such as oesophageal adenocarcinomas (6).

Female sex has been considered one of the most important prognostic factors affecting melanoma in previous studies $(7,8)$. Multiple studies have found that females have a lower long-term melanoma mortality rate than men. However, this protective effect may be affected by age (9-11). Studies have found that before the age of menopause, the incidence melanoma located on the trunk is similar in males and females, but after menopause, the incidence in females declines significantly (12). Another study also found that in patients with stage I melanoma, the survival advantage in female patients in the 46- to 59-yearold group was not significant, but in females over 60 years old, the survival advantage was obvious (10).

Considering that the 8 th edition of the staging system readjusted the distribution and the definition of stage $\mathrm{T} 1$, we used malignant melanoma data from the SEER database to specifically quantify the effects of sex on early malignant melanoma in different age groups and observe whether a sex advantage could be observed in all age groups. We present the following article in accordance with the STROBE reporting checklist (Available at http://dx.doi.org/10.21037/ atm-20-3845).

\section{Methods}

Patients were selected from the SEER database. The current SEER database is a population-based cancer registry sponsored by the National Cancer Institute, covering approximately $34.6 \%$ of the U.S. population. Every researcher has access to it (https://seer.cancer.gov). We selected individuals diagnosed with skin melanoma between 2004 and 2015 because the baseline data of patients wasn't complete before 2004. Based on the 8th edition of the melanoma staging system, patients diagnosed with pathological stages T1a-T3a, N0 and M0 were enrolled. Other enrolment criteria included participation in active follow-up and skin melanoma as the primary malignant tumour. Patients were excluded if diagnosed at autopsy or if the cause of death was unknown.

Baseline data, including patient information (age, sex), and melanoma characteristics (location, subtype, Clark class, Breslow thickness, mitotic rate, and ulceration) were obtained from the SEER database. We reclassified cases to match the 8th edition of the melanoma staging system according to melanoma characteristics above. In this study, overall survival (OS) and melanoma-specific survival (MSS), which were collected from the SEER database through December 31, 2015, were used to evaluate outcomes. OS and MSS were defined as the interval from diagnosis until death from any cause and as a result of melanoma, respectively.

The study was conducted in accordance with the Declaration of Helsinki (as revised in 2013).

\section{Statistical analysis}

We used one-way ANOVA with a multiple comparison post hoc test and a chi-square test to analyse all continuous and categorical variables with normal distributions. The Kruskal-Wallis test was used to analyse data with non-normal distributions after adjusting for multiple confounders. Kaplan-Meier survival curves were estimated 
Table 16 th, 7th and 8th edition of staging system in T1 category

\begin{tabular}{|c|c|c|c|c|c|c|}
\hline & \multicolumn{2}{|r|}{ 6th } & \multicolumn{2}{|r|}{ 7th } & \multicolumn{2}{|r|}{ 8th } \\
\hline T1a & $\leq 1.0 \mathrm{~mm}$ & $\begin{array}{l}\text { Without ulceration and } \\
\text { level II/III }\end{array}$ & $\leq 1.0 \mathrm{~mm}$ & $\begin{array}{l}\text { Without ulceration and } \\
\text { mitosis }<1 / \mathrm{mm}^{2}\end{array}$ & $<0.8 \mathrm{~mm}$ & Without ulceration \\
\hline $\mathrm{T} 1 \mathrm{~b}$ & $\leq 1.0 \mathrm{~mm}$ & $\begin{array}{l}\text { With ulceration and } \\
\text { level IV/N }\end{array}$ & $\leq 1.0 \mathrm{~mm}$ & $\begin{array}{l}\text { With ulceration or } \\
\text { mitosis } \geq 1 / \mathrm{mm}^{2}\end{array}$ & $\begin{array}{l}<0.8 \mathrm{~mm} \\
0.8-1.0 \mathrm{~mm}\end{array}$ & $\begin{array}{l}\text { With ulceration } \\
\text { With or without ulceration }\end{array}$ \\
\hline
\end{tabular}

AJCC $6^{\text {th }}-8^{\text {th }}$ edition melanoma stage IA - IIA subgroups

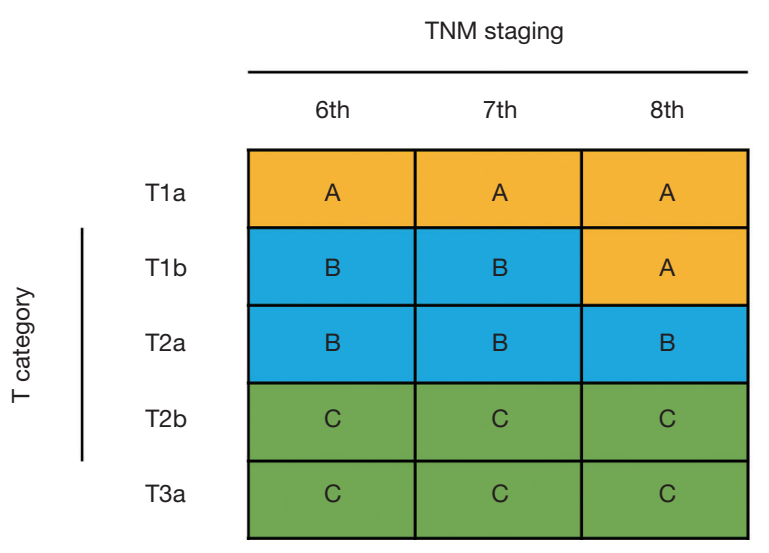

Figure 16 th, 7 th and 8th edition of staging system in early melanoma.

and compared with the log-rank test. Cox regression analysis was used to calculate hazard ratios (HRs) and $95 \%$ CIs. Risk factors with a $\mathrm{P}$ value $<0.1$ in the univariate analysis and with great importance were selected for the multivariable analysis. A two-sided $\mathrm{P}$ value $<0.05$ was considered statistically significant. We used SPSS 24.0 (SPSS, Chicago, IL, USA) and GraphPad Prism 7.0 (GraphPad Software, San Diego, CA, USA) for the analyses. The current study was approved by the ethics committee of Nanjing Drum Tower Hospital Clinical College of Nanjing Medical University, the Affiliated Hospital of Nanjing University Medical School (2017-175-01).

\section{Results}

A total of 115,576 patients were enrolled in the study. Among them, 62,938 were male and 52,638 were female (Table 2). In each age group, the number of patients is basically similar, respectively 37,149 cases $(\leq 50$ years age group), 26,847 cases (51-60 years age group), 25,237 cases (61-70 years old group), and 26,343 cases ( $>70$ years age group). We conducted a comprehensive analysis of tumor stage, location, pathological subtype, Clark grade, mitotic rate and ulceration. In the comparison of men and women in each group, there was no significant difference in the distribution of $T$ category and stage in the $>70$ years age group, while all other groups had significant differences $(\mathrm{P}<0.001)$. The distribution of tumors was significantly different in all groups $(\mathrm{P}<0.001)$. Among them, males had more cases on the trunk (41.2\%), while females had a higher incidence of lower limbs (30.4\%). In terms of pathological subtypes, males have more Lentigo maligna melanoma than normal type melanoma and Superficial spreading, while females have more Acral lentiginous than males. Clark grades were significantly different except for the $>70$ years age group $(\mathrm{P}=0.179)$. Although there was no significant difference in mitotic rate among overall patients group, there were significant differences in all age groups except the $61-70$ years age group $(\mathrm{P}=0.255)$. There was no significant difference between the $61-70$ years age group $(\mathrm{P}=0.638)$ and in the $>70$-year-old group $(\mathrm{P}=0.497)$.

In terms of long-term survival curves, the survival 
Table 2 Baseline data in skin melanoma patients

\begin{tabular}{|c|c|c|c|c|c|c|c|c|c|c|c|c|c|c|c|}
\hline & \multicolumn{3}{|c|}{ All patients $(n=115,576)$} & \multicolumn{3}{|c|}{$\leq 50$ years age group $(n=37,149)$} & \multicolumn{3}{|c|}{$51-60$ years age group $(n=26,847)$} & \multicolumn{3}{|c|}{$61-70$ years age group $(n=25,237)$} & \multicolumn{3}{|c|}{$>70$ years age group $(\mathrm{n}=26,343)$} \\
\hline & Male $(n=62,938)$ & Female $(n=52,638)$ & $P$ value & Male $(n=15,291)$ & Female $(n=21,858)$ & $P$ value & Male $(n=15,227)$ & Female $(n=11,620)$ & $P$ value & Male $(n=15,995)$ & Female $(n=9,242)$ & $P$ value & Male $(n=16,425)$ & Female $(n=9,918)$ & $P$ value \\
\hline \multicolumn{16}{|l|}{ Stage } \\
\hline IA & 48,606 (77.2\%) & $42,482(80.7 \%)$ & $<0.001$ & 12,185 (79.7\%) & $18,364(84.0 \%)$ & $<0.001$ & 11,969 (78.6\%) & $9,545(82.1 \%)$ & $<0.001$ & $12,470(78.0 \%)$ & 7,415 & $<0.001$ & 11,982 (73.0\%) & 7,158 (72.2\%) & 0.179 \\
\hline IB & $8,849(14.1 \%)$ & 6,517 (12.4\%) & & 2,095 (13.7\%) & $2,470(11.3 \%)$ & & $2,149(14.1 \%)$ & $1,385(11.9 \%)$ & & $2,183(13.6 \%)$ & 1,155 & & 2,422 (14.7\%) & $1,507(15.2 \%)$ & \\
\hline IIA & $5,483(8.7 \%)$ & 3,639 (6.9\%) & & $1,011(6.6 \%)$ & $1,024(4.7 \%)$ & & $1,109(7.3 \%)$ & $690(5.9 \%)$ & & $1,342(8.4 \%)$ & 672 & & $2,021(12.3 \%)$ & $1,253(12.6 \%)$ & \\
\hline \multicolumn{16}{|l|}{ T category } \\
\hline T1a & $42,177(67.0 \%)$ & $37,324(70.9 \%)$ & $<0.001$ & $10,583(69.2 \%)$ & $16,288(74.5 \%)$ & $<0.001$ & 10,398 (68.3\%) & $8,404(72.3 \%)$ & $<0.001$ & $10,905(68.2 \%)$ & $6,545(70.8 \%)$ & $<0.001$ & $10,291(62.7 \%)$ & $6,087(61.3 \%)$ & 0.055 \\
\hline T2a & $6,429(10.2 \%)$ & $5,158(9.8 \%)$ & & $1,602(10.5 \%)$ & $2,076(9.5 \%)$ & & $1,571(10.3 \%)$ & $1,141(9.8 \%)$ & & $1,565(9.8 \%)$ & $870(9.4 \%)$ & & $1,691(10.3 \%)$ & $1,071(10.8 \%)$ & \\
\hline Тза & $8,849(14.1 \%)$ & 6,517 (12.4\%) & & 2,095 (13.7\%) & 2,470 (11.3\%) & & $2,149(14.1 \%)$ & $1,385(11.9 \%)$ & & 2,183 (13.6\%) & $1,155(12.5 \%)$ & & 2,422 (14.7\%) & $1,507(15.2 \%)$ & \\
\hline T4a & $1,965(3.1 \%)$ & $1,360(2.6 \%)$ & & $355(2.3 \%)$ & $366(1.7 \%)$ & & $396(2.6 \%)$ & $289(2.5 \%)$ & & $487(3.0 \%)$ & $277(3.0 \%)$ & & $727(4.4 \%)$ & $448(4.6 \%)$ & \\
\hline T5a & $3,518(5.6 \%)$ & $2,259(4.3 \%)$ & & $656(4.3 \%)$ & $658(3.0 \%)$ & & $713(4.7 \%)$ & $401(3.5 \%)$ & & $855(5.3 \%)$ & $395(4.3 \%)$ & & $1,294(7.9 \%)$ & $805(8.1 \%)$ & \\
\hline \multicolumn{16}{|l|}{ Location } \\
\hline Head and neck & $15,614(24.8 \%)$ & 6,455 (12.3\%) & $<0.001$ & 2,777 (18.2\%) & $1,808(8.3 \%)$ & $<0.001$ & 2,929 (19.2\%) & $1,047(9.0 \%)$ & $<0.001$ & 4,034 (25.2\%) & 1,225 (13.3\%) & $<0.001$ & $5,874(35.8 \%)$ & 2,375 (23.4\%) & $<0.001$ \\
\hline Trunk & 25,923 (41.2\%) & $14,429(27.4 \%)$ & & 7,104 (46.5\%) & 7,268 (33.3\%) & & 6,939 (45.6\%) & 3,183 (27.4\%) & & 6,497 (40.6\%) & 2,218 (24.0\%) & & $5,383(32.8 \%)$ & $1,760(17.8 \%)$ & \\
\hline Upper limb and shoulder & $15,467(24.6 \%)$ & $15,618(29.7 \%)$ & & $3,311(21.7 \%)$ & $5,429(24.8 \%)$ & & $3,784(24.9 \%)$ & $3,724(32.0 \%)$ & & $4,204(26.3 \%)$ & $3,160(34.2 \%)$ & & $4,168(25.4 \%)$ & 3,305 (33.3\%) & \\
\hline Lower limb and hip & $5,749(9.1 \%)$ & 15,992 (30.4\%) & & 2,056 (13.4\%) & $7,289(33.3 \%)$ & & $1,529(10.0 \%)$ & 3,632 (31.3\%) & & $1,218(7.6 \%)$ & $2,620(28.3 \%)$ & & $546(3.3 \%)$ & $2,451(24.8 \%)$ & \\
\hline Others & $185(0.3 \%)$ & $144(0.3 \%)$ & & $43(0.3 \%)$ & $64(0.3 \%)$ & & $46(0.3 \%)$ & $34(0.3 \%)$ & & $42(0.3 \%)$ & $19(0.2 \%)$ & & $54(0.3 \%)$ & $27(0.8 \%)$ & \\
\hline \multicolumn{16}{|l|}{ Subtype of melanoma } \\
\hline Superficial spreading & 22,545 (35.8\%) & 20,998 (39.9\%) & $<0.001$ & 6,619 (43.3\%) & $9,854(45.1 \%)$ & 0.188 & $5,847(38.4 \%)$ & $4,757(40.9 \%)$ & 0.078 & 5,372 (33.6\%) & 3,414 (36.9\%) & 0.004 & $4,707(28.7 \%)$ & $2,973(30.0 \%)$ & 0.511 \\
\hline Lentigo maligna melanoma & $5,641(9.0 \%)$ & $2,675(5.1 \%)$ & & $424(2.8 \%)$ & $302(1.4 \%)$ & & $1,015(6.7 \%)$ & $452(3.9 \%)$ & & $1,749(10.9 \%)$ & $751(8.1 \%)$ & & 2,453 (15.0\%) & $1,170(11.8 \%)$ & \\
\hline Acral lentiginous & $340(0.5 \%)$ & $522(1.0 \%)$ & & $78(0.5 \%)$ & $155(0.7 \%)$ & & $60(0.4 \%)$ & $112(1.0 \%)$ & & $81(0.6 \%)$ & $107(1.2 \%)$ & & $121(0.7 \%)$ & $148(1.5 \%)$ & \\
\hline Others & 2,246 (3.6\%) & $1,638(3.1 \%)$ & & $496(3.2 \%)$ & $618(2.8 \%)$ & & $484(3.2 \%)$ & $346(3.0 \%)$ & & $536(3.4 \%)$ & $279(3.0 \%)$ & & $730(4.4 \%)$ & $395(4.0 \%)$ & \\
\hline Melanoma not specified & $29,525(46.9 \%)$ & $24,899(47.3 \%)$ & & $7,140(46.7 \%)$ & 10,290 (47.1\%) & & $7,244(47.6 \%)$ & $5,554(47.8 \%)$ & & $7,633(47.7 \%)$ & $4,363(47.2 \%)$ & & $7,508(45.7 \%)$ & 4,692 (47.3\%) & \\
\hline \multicolumn{16}{|l|}{ Clark class } \\
\hline$\|$ & 23,078 (36.7\%) & $20,870(39.6 \%)$ & $<0.001$ & $5,699(37.3 \%)$ & $9,257(42.4 \%)$ & $<0.001$ & $5,771(37.9 \%)$ & 4,641 (39.9\%) & 0.002 & $5,948(37.2 \%)$ & 3,587 (38.8\%) & 0.001 & $5,660(34.5 \%)$ & 3,385 (34.1\%) & 0.179 \\
\hline IIII & $15,800(25.1 \%)$ & $13,350(25.4 \%)$ & & $4,286(28.0 \%)$ & $5,890(27.0 \%)$ & & 3,917 (25.8\%) & 2,990 (25.7\%) & & 3,823 (23.9\%) & 2,286 (24.7\%) & & 3,774 (23.0\%) & $2,184(22.0 \%)$ & \\
\hline IV & $16,433(26.1 \%)$ & $12,365(23.5 \%)$ & & 3,822 (25.0\%) & 4,659 (21.3\%) & & 3,861 (25.4\%) & 2,643 (22.7\%) & & 4,144 (25.9\%) & $2,187(23.7 \%)$ & & $4,606(28.0 \%)$ & 2,876 (29.0\%) & \\
\hline v & $651(1.0 \%)$ & $449(0.9 \%)$ & & $90(0.6 \%)$ & $81(0.4 \%)$ & & $122(0.8 \%)$ & $64(0.6 \%)$ & & $131(0.8 \%)$ & $87(0.9 \%)$ & & $308(1.9 \%)$ & $217(2.2 \%)$ & \\
\hline Others & 6,976 (11.1\%) & $5,604(10.6 \%)$ & & 1,394 (9.1\%) & 1,971 (9.0\%) & & 1,556 (10.2\%) & 1,282 (11.0\%) & & 1,949 (12.2\%) & 1,095 (11.8\%) & & 2,077 (12.6\%) & $1,256(12.7 \%)$ & \\
\hline \multicolumn{16}{|l|}{ Mitotic rate } \\
\hline$<1$ & $19,346(30.7 \%)$ & $16,140(30.7 \%)$ & 0.550 & 3,956 (25.9\%) & 6,175 (28.3\%) & $<0.001$ & $4,534(29.8 \%)$ & 3,798 (32.7\%) & $<0.001$ & $5,663(35.4 \%)$ & $3,267(35.3 \%)$ & 0.255 & $5,193(31.6 \%)$ & 2,900 (29.2\%) & 0.004 \\
\hline$=1$ & $5,249(8.3 \%)$ & 4,590 (8.7\%) & & $1,249(8.2 \%)$ & $1,817(8.3 \%)$ & & 1,322 (8.7\%) & 1,028 (8.8\%) & & 1,377 (8.6\%) & $909(9.8 \%)$ & & 1,301 (7.9\%) & $836(8.4 \%)$ & \\
\hline$\geq 2$ & 6,563 (10.4\%) & 5,144 (9.8\%) & & $1,351(8.8 \%)$ & 1,738 (8.0\%) & & $1,520(10.0 \%)$ & $1,147(9.9 \%)$ & & 1,722 (10.8\%) & 985 (10.7\%) & & $1,970(12.0 \%)$ & $1,274(12.8 \%)$ & \\
\hline Unknown & $31,780(50.5 \%)$ & $26,764(50.8 \%)$ & & 8,735 (57.1\%) & 12,128 (55.5\%) & & $7,851(51.6 \%)$ & $5,647(48.6 \%)$ & & 7,233 (45.2\%) & $4,081(44.2 \%)$ & & 7,961 (48.5\%) & 4,908 (49.5\%) & \\
\hline \multicolumn{16}{|l|}{ Ulceration } \\
\hline No & $59,063(93.8 \%)$ & 49,812 (94.6\%) & $<0.001$ & $14,557(95.2 \%)$ & $21,003(96.1 \%)$ & $<0.001$ & 14,410 (94.6\%) & 11,065 (95.2\%) & 0.030 & 15,051 (94.1\%) & 8,683 (94.0\%) & 0.638 & $15,045(91.6 \%)$ & $9,061(91.4 \%)$ & 0.497 \\
\hline Yes & $3,853(6.1 \%)$ & 2,811 (5.3\%) & & $731(4.8 \%)$ & $652(3.0 \%)$ & & $810(5.3 \%)$ & $551(4.7 \%)$ & & 938 (5.9\%) & $557(6.0 \%)$ & & 1,374 (8.4\%) & $851(8.6 \%)$ & \\
\hline Unknown & $22(0.0 \%)$ & $15(0.0 \%)$ & & $3(0.0 \%)$ & $3(0.0 \%)$ & & $7(0.0 \%)$ & $4(0.0 \%)$ & & $6(0.0 \%)$ & $2(0.0 \%)$ & & $6(0.0 \%)$ & $6(0.0 \%)$ & \\
\hline
\end{tabular}


Overall

Stage IA

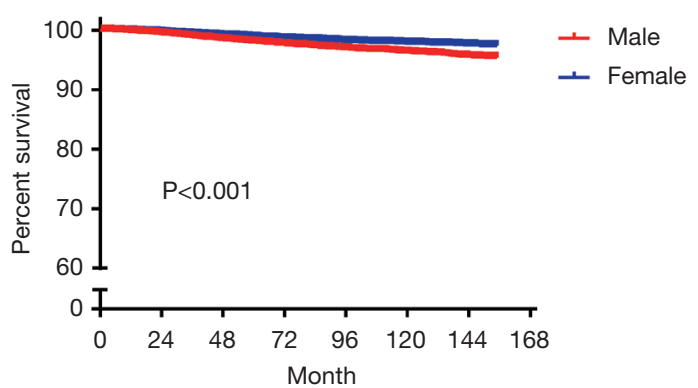

Stage IIA

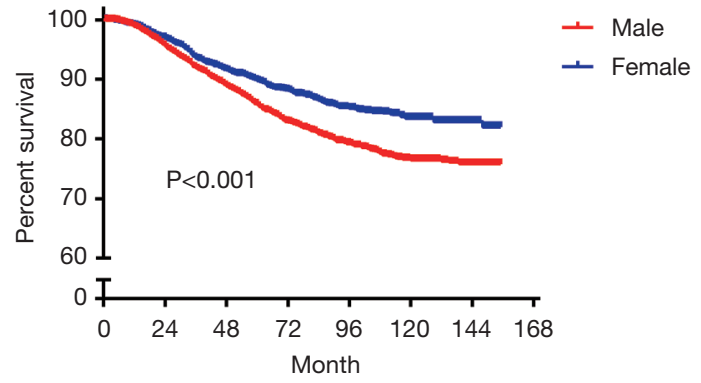

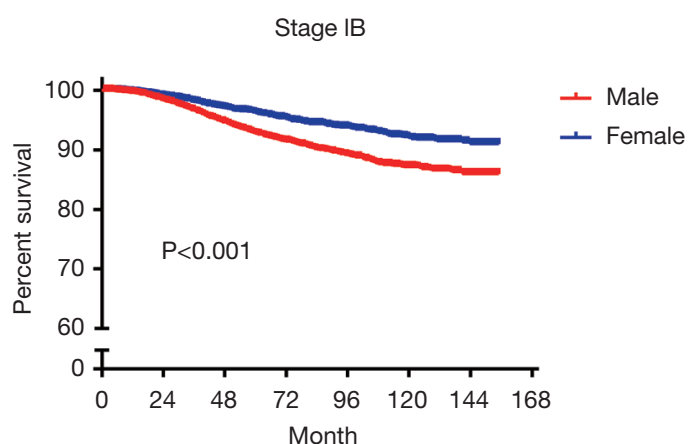

Figure 2 Survival curve of MSS in all patients of different stages. MSS, melanoma-specific survival.

rates of males and females with stage IA-IIA melanoma were significantly different among the patients $(\mathrm{P}<0.001)$ (Figure 2). In a further analysis of each age group, it was found that there were significant differences in each of the age groups for stage IA $(\mathrm{T} 1 \mathrm{a}+\mathrm{T} 1 \mathrm{~b})$, stage IB $(\mathrm{T} 2 \mathrm{a})$ and stage IIA (T2b + T3a) (Figures 3-5). Considering that in a previous study, the age-related survival advantage of females with stage I melanoma may have been related to the stage adjustment, we separately analysed those with grades T1a and T1b (Figures 6,7). In only the 61-70 years age group with grade $\mathrm{T} 1 \mathrm{~b}(\mathrm{P}=0.054)$ was there no difference between males and females. In all other groups, females still maintained a sex advantage.

In the Cox analysis, for each group, we conducted a separate analysis considering age and additional analyses after adding other factors for correction (Table 3). In all the patient groups, the data indicated a significant female survival advantage $(\mathrm{P} \leq 0.001)$. Each age group in the stage IA group had a female survival advantage. In the stage IB group, after correction, the $\leq 50$ years age group $(\mathrm{P}=0.099$, HR: $1.294,95 \%$ CI: $0.953-1.758)$ and 51-60 years age group ( $\mathrm{P}=0.522$, HR: $1.109,95 \%$ CI: 0.808-1.522) showed no significant differences in survival between males and females. However, the $>60$ years age group showed a female survival advantage. The situation in the stage IIA group was interesting; the $51-60$ years age group $(\mathrm{P}=0.122$, HR: 1.305 , 95\% CI: $0.931-1.831)$ and the $>70$ years age group $(\mathrm{P}=0.161$, HR: $1.148,95 \%$ CI: $0.947-1.392)$ showed no significant differences in survival, but there was a significant difference in the $61-70$ years age group $(\mathrm{P}=0.009$, HR: $1.481,95 \%$ CI: 1.103-1.990). Besides, the survival curve trend (Figures 3-5) was similar and no crossing, and it meant the independent variable(sex) meets the requirement of proportional hazards assumption.

\section{Discussion}

Based on the 8th edition of the AJCC malignant tumour staging system, we observed many changes in the different types of tumours, but these changes were not precise. A study found that in the 8th edition of the TNM staging for oesophageal adenocarcinoma, after adjusting for the new IA stage, better resolution than the 7 th edition was not obtained (6). For early skin melanoma, a thickness of 


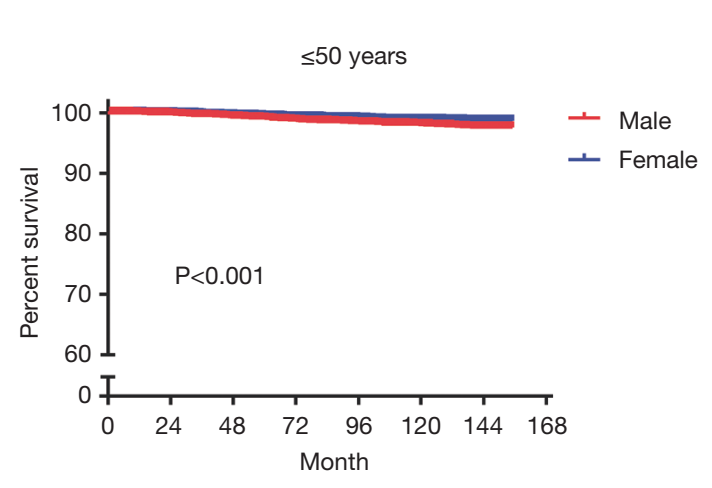

Stage IA
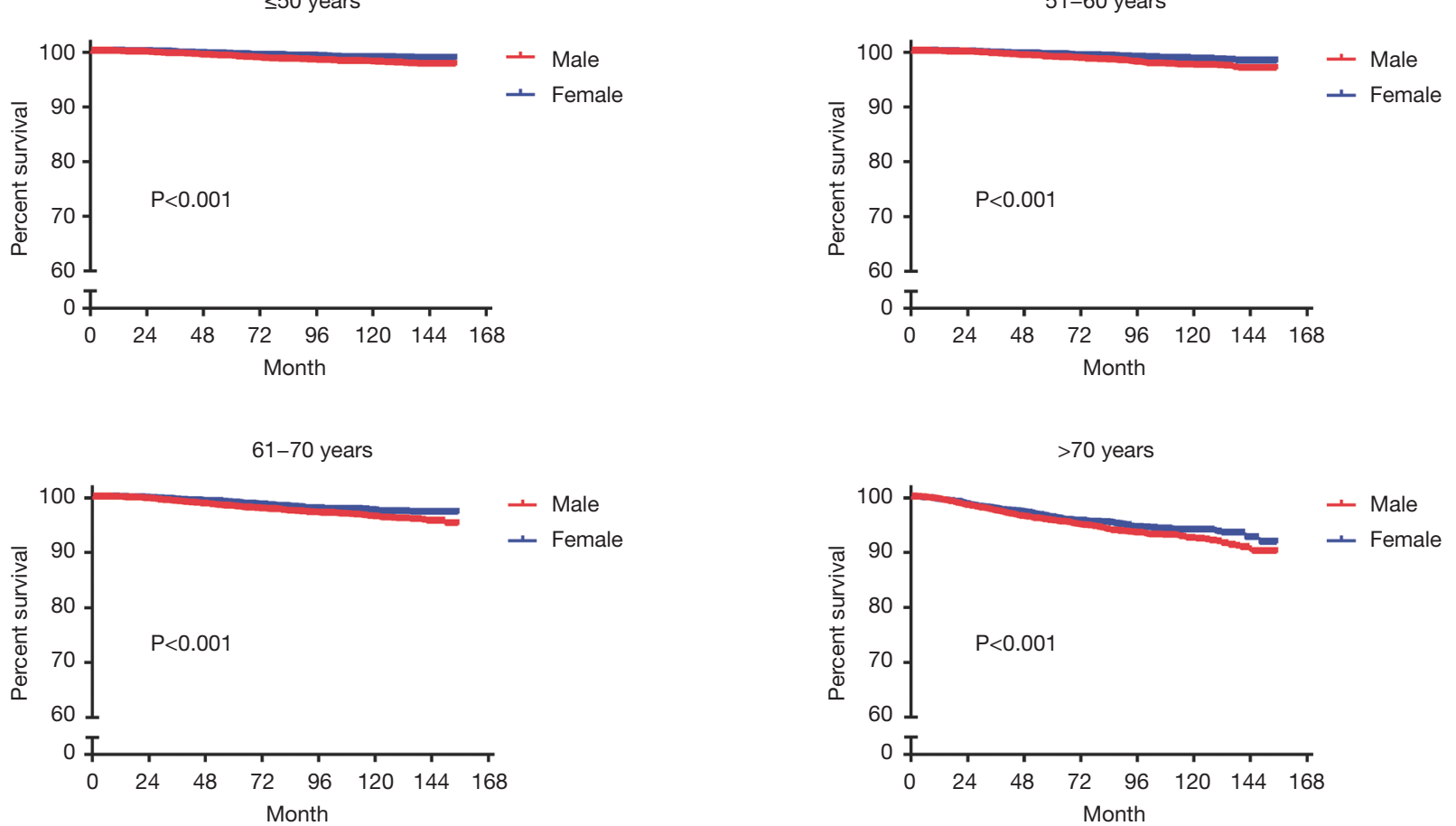

Figure 3 Survival curve of MSS in stage IA patients in different ages groups. MSS, melanoma-specific survival.

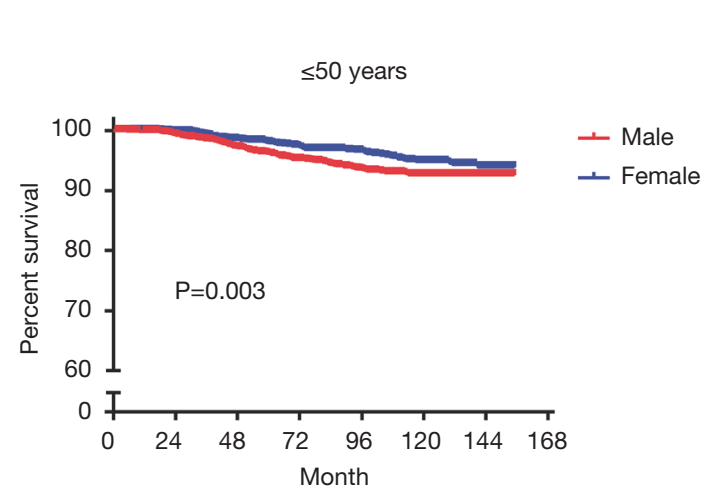

Stage IB
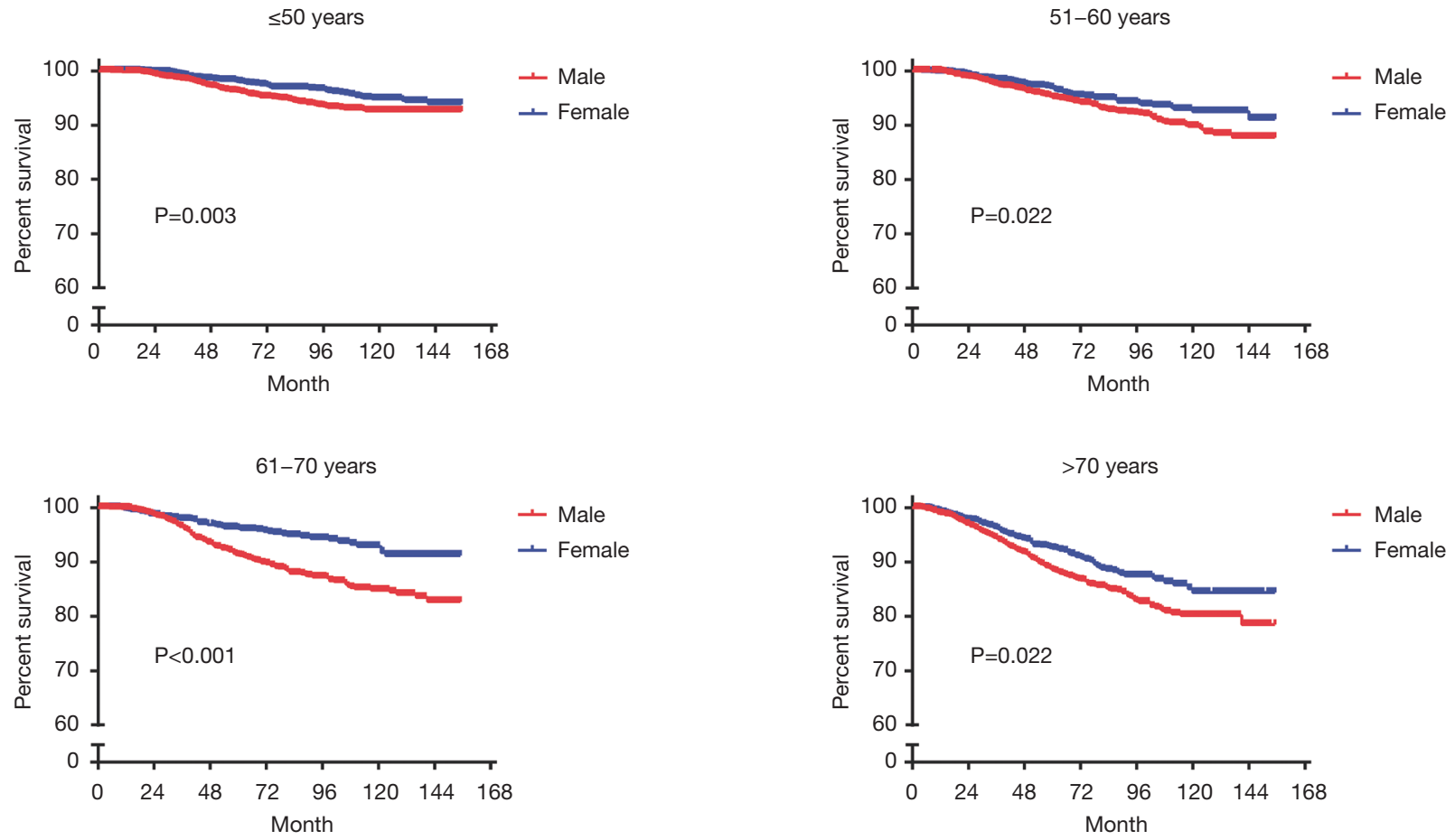

Figure 4 Survival curve of MSS in stage IB patients in different ages groups. MSS, melanoma-specific survival. 


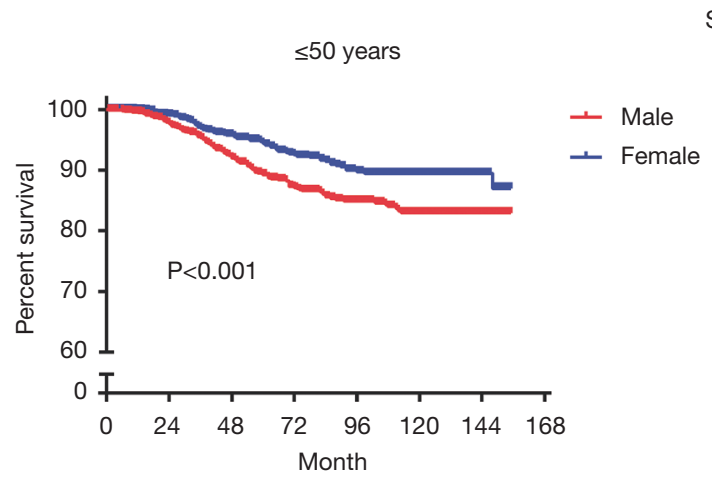

Stage IIA
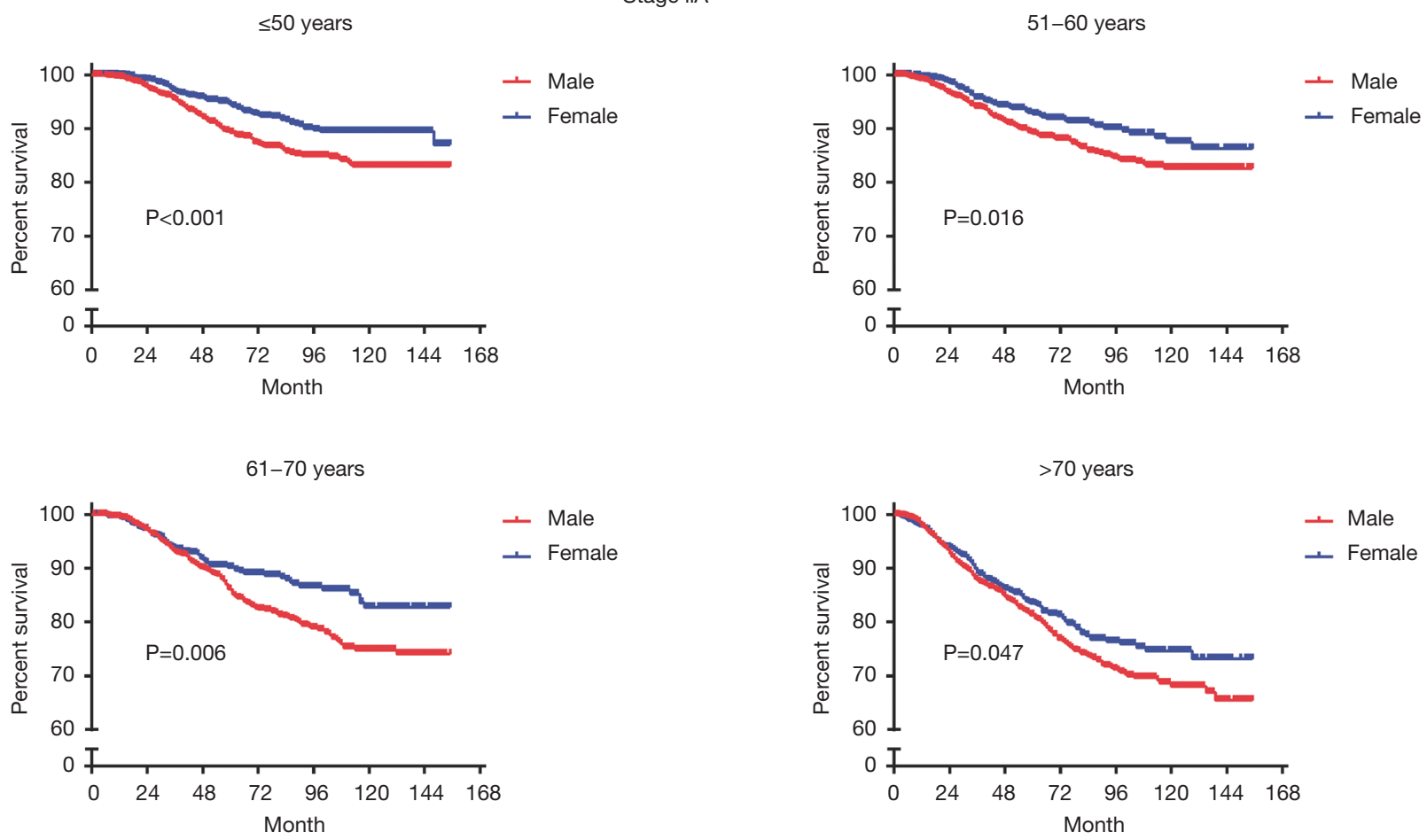

Figure 5 Survival curve of MSS in stage IIA patients in different ages groups. MSS, melanoma-specific survival.

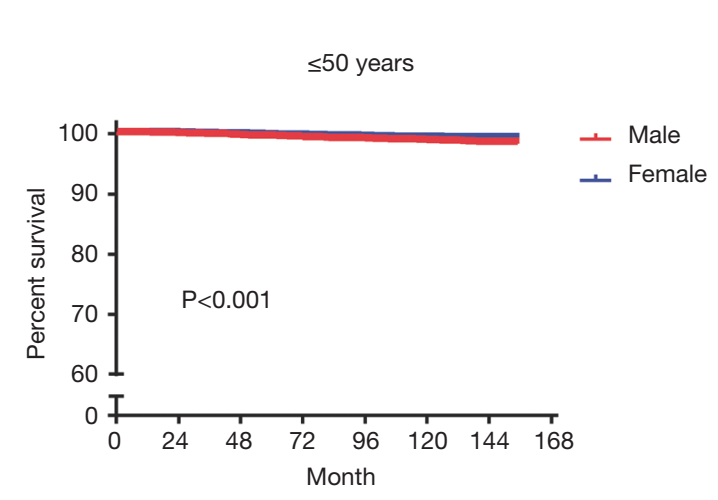

T1aNOMO
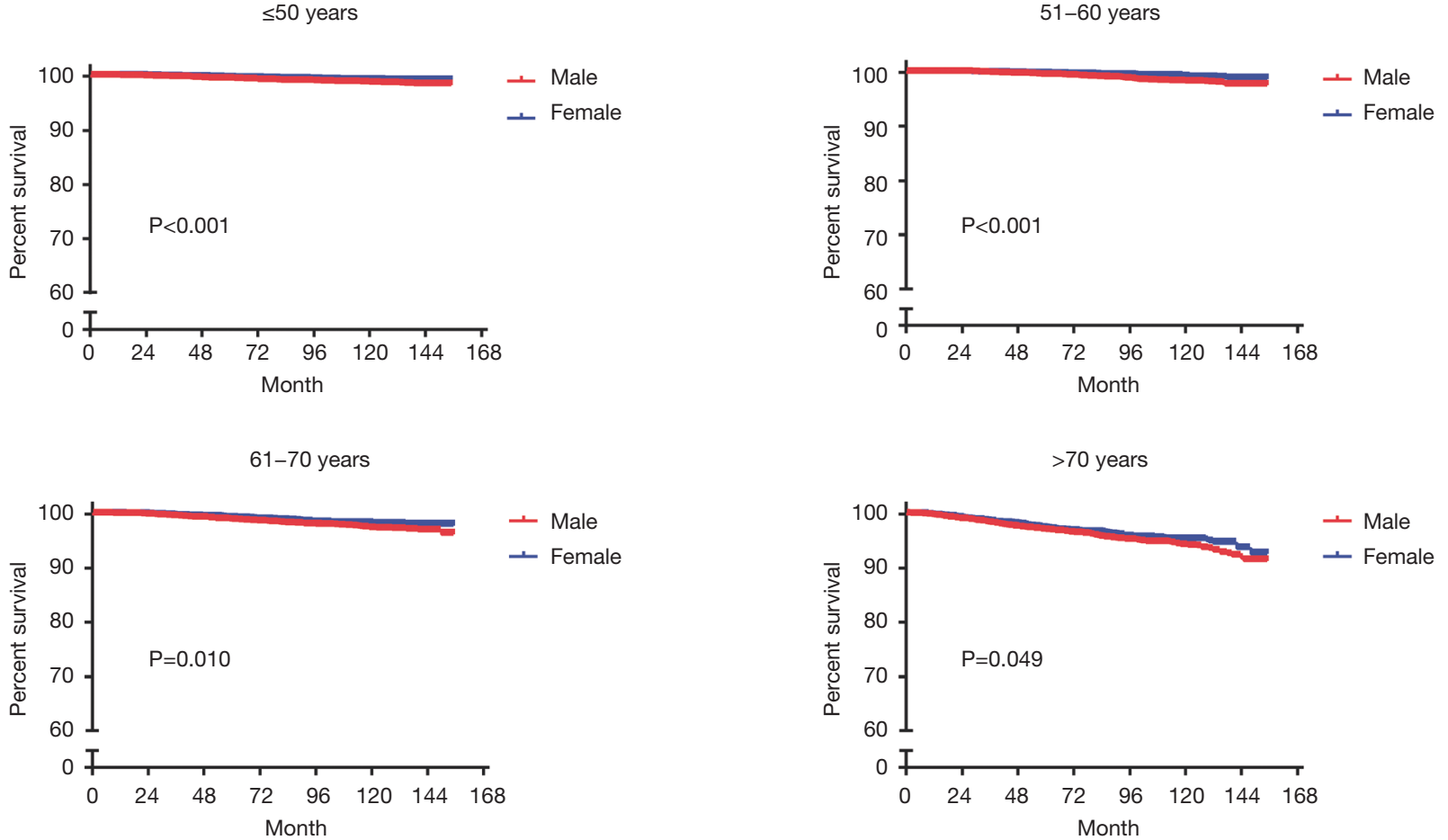

Figure 6 Survival curve of MSS in T1aN0M0 patients in different ages groups. MSS, melanoma-specific survival. 
T1bNOM0
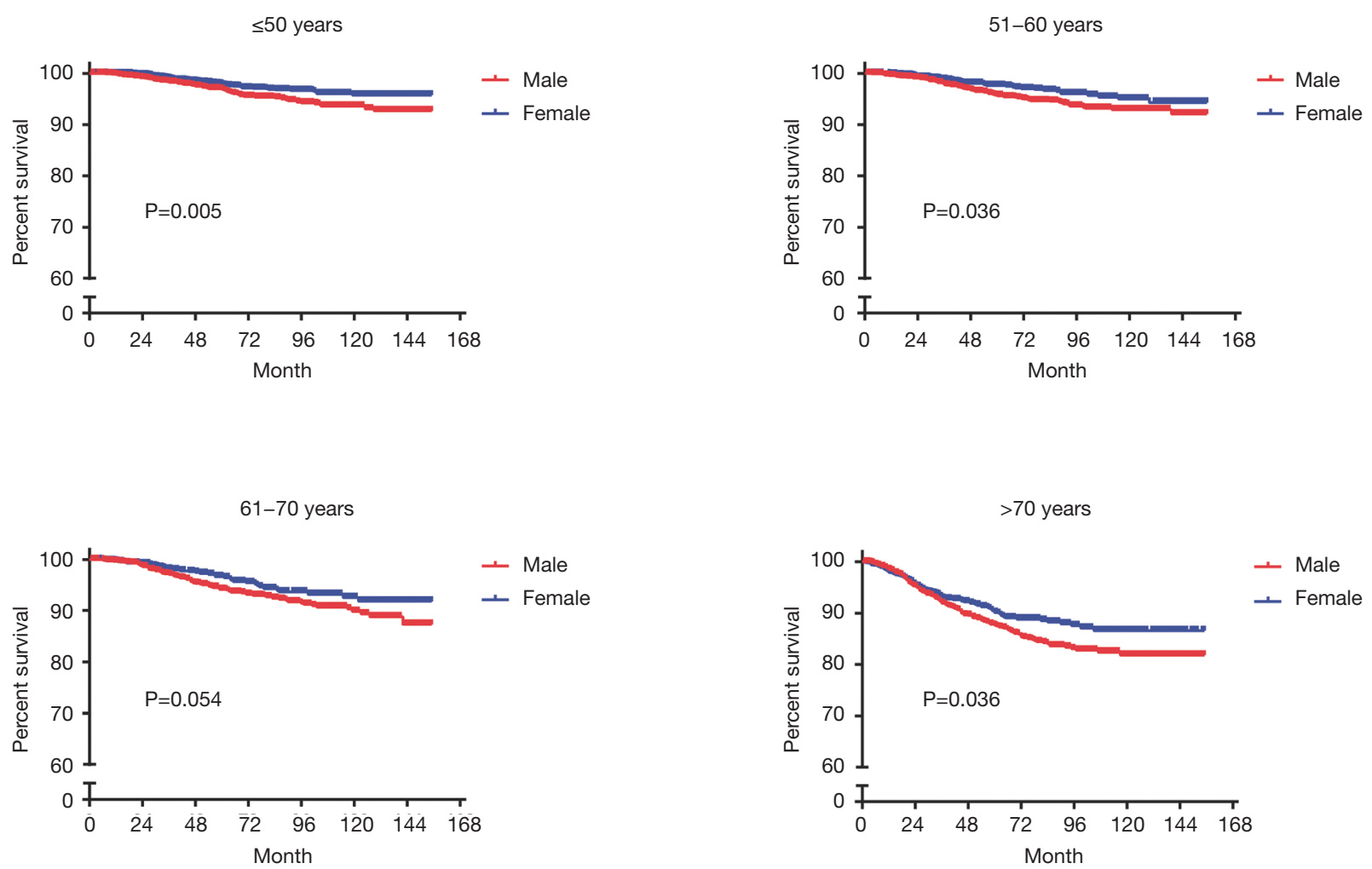

Figure 7 Survival curve of MSS in T1bN0M0 patients in different ages groups. MSS, melanoma-specific survival.

$0.8 \mathrm{~cm}$ was introduced, and the factors indicative of stage I melanoma was redistributed. Although neither sex nor age are factors that need to be considered in AJCC staging, we found that in early malignant melanoma patients, under the new staging system, in stage I patients, females had significant survival advantages in the different age groups, suggesting that the 8 th edition of the staging system may show better differentiation than previous editions. In a further analysis of T1a and T1b patients, we found that only the 61-70 years age subgroup of the T1b group presented differences between males and females, with values slightly lower than the critical value $(\mathrm{P}=0.054)$, further demonstrating good performance of the new staging system.

The advantage of female sex in malignant melanoma is very significant, but this phenomenon is not unique to malignant melanoma. In breast cancer, the incidence rates before and after menopause also change significantly (12). Some studies believe that this may be related to oestrogen, but there is currently no strong evidence for this theory. The change in survival advantage with age has not been clearly explained. Some studies have found that the female survival advantage in melanoma patients is lost during pregnancy, but females in the postpartum period regain their survival advantage (7). This verifies the relevance of sex hormones. Some studies have suggested that oestrogen increases the number of melanocytes and regulates melanin concentration (13). Some genetic studies have also found that mutations in the melanocortin receptor (MC1R) regulate and improve survival in females. The goal is to enhance DNA repair and antioxidant capacity, and oestrogen can mediate oxidative stress and promote the induction of a response. Reactive oxygen species (ROS) are produced, which leads to cell death (14); therefore, the incidence of melanoma in females before and after menopause will be increased. However, these factors do not fully explain the effect of age on female survival advantage, and further research is still needed to verify the role of sex hormones in malignant melanoma.

In our study, the Cox analysis found that in the stage IB group, the phenomenon of female survival advantage occurred only when the patients were $>60$ years old 
Table 3 Cox analyze of male $v$ s. female according to age groups

\begin{tabular}{|c|c|c|c|c|c|}
\hline Subgroups & Variables & $N$ (male vs. female) & $P$ value & $\mathrm{HR}$ & $95 \% \mathrm{Cl}$ \\
\hline \multicolumn{6}{|l|}{ All patients } \\
\hline \multirow[t]{2}{*}{$\leq 50$ years } & Unadjusted & 15291:21858 & $<0.001$ & 1.924 & $1.646-2.248$ \\
\hline & $\begin{array}{c}\text { Location, Clark class, Mitotic rate and } \\
\text { Ulceration }\end{array}$ & & $<0.001$ & 1.436 & $1.223-1.686$ \\
\hline \multirow[t]{2}{*}{$61-70$ years } & Unadjusted & 15995:9242 & $<0.001$ & 1.712 & $1.466-2.000$ \\
\hline & $\begin{array}{c}\text { Location, Clark class, Mitotic rate and } \\
\text { Ulceration }\end{array}$ & & $<0.001$ & 1.519 & $1.290-1.789$ \\
\hline \multicolumn{6}{|l|}{ Stage IA } \\
\hline \multirow[t]{2}{*}{$\leq 50$ years } & Unadjusted & $12185: 18364$ & $<0.001$ & 1.812 & $1.437-2.285$ \\
\hline & $\begin{array}{l}\text { Location, Clark class, Mitotic rate and } \\
\text { Ulceration }\end{array}$ & & $<0.001$ & 1.371 & $1.079-1.741$ \\
\hline \multirow[t]{2}{*}{$51-60$ years } & Unadjusted & 11969:9545 & $<0.001$ & 1.793 & $1.368-2.349$ \\
\hline & $\begin{array}{l}\text { Location, Clark class, Mitotic rate and } \\
\text { Ulceration }\end{array}$ & & $<0.001$ & 1.527 & $1.146-2.034$ \\
\hline $61-70$ years & Unadjusted & $12470: 7415$ & 0.001 & 1.505 & $1.190-1.904$ \\
\hline \multicolumn{6}{|l|}{ Stage IB } \\
\hline \multirow[t]{2}{*}{$\leq 50$ years } & Unadjusted & 2095:2470 & 0.003 & 1.571 & $1.164-2.119$ \\
\hline & $\begin{array}{c}\text { Location, Clark class, Mitotic rate and } \\
\text { Ulceration }\end{array}$ & & 0.099 & 1.294 & $0.953-1.758$ \\
\hline \multirow[t]{2}{*}{$51-60$ years } & Unadjusted & 2149:1385 & 0.023 & 1.429 & $1.051-1.943$ \\
\hline & $\begin{array}{c}\text { Location, Clark class, Mitotic rate and } \\
\text { Ulceration }\end{array}$ & & 0.522 & 1.109 & $0.808-1.522$ \\
\hline \multirow[t]{2}{*}{$61-70$ years } & Unadjusted & 2183:1155 & $<0.001$ & 2.110 & $1.550-2.875$ \\
\hline & $\begin{array}{l}\text { Location, Clark class, Mitotic rate and } \\
\text { Ulceration }\end{array}$ & & 0.001 & 1.731 & $1.254-2.390$ \\
\hline \multirow[t]{2}{*}{$>70$ years } & Unadjusted & $2422: 1507$ & 0.002 & 1.426 & $1.140-1.784$ \\
\hline & $\begin{array}{c}\text { Location, Clark class, Mitotic rate and } \\
\text { Ulceration }\end{array}$ & & 0.006 & 1.392 & $1.098-1.764$ \\
\hline
\end{tabular}

Table 3 (continued) 
Table 3 (continued)

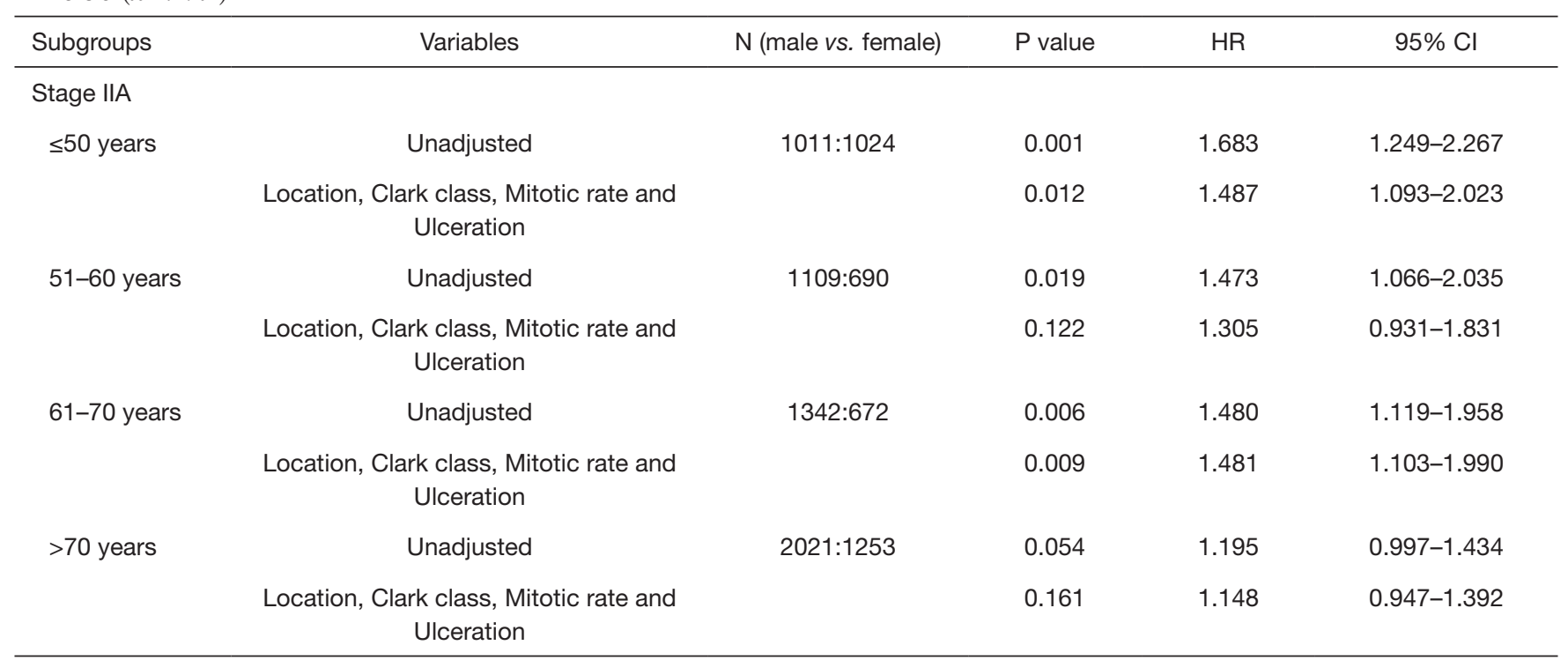

(although the survival curve was also significantly different for those under 60 years old), similar to previous results. Because in the 8th edition, the composition of stage IB was T2aN0M0, the number of patients in the T2 stage was the same as those in the $\mathrm{T} 2$ stage in the 6th edition and the 7 th edition. However, due to the redistribution of the T1 stage, the number of patients was completely different from the number of patients in the 6th and 7 th editions. Therefore, in the IA group according to the new classification, which comprises $\mathrm{T} 1 \mathrm{a}+\mathrm{T} 1 \mathrm{~b}$, we did not observe a female survival advantage that changed with age. This also further illustrates the rationality of the 8 th edition and the redistribution of $\mathrm{T} 1$ stage indicators.

This sex-specific advantage changed slightly in the stage IIA group. We found that although the survival curves still showed differences, after adjusting for tumour location, Clark grade, mitotic rate, and ulceration, in the 51-60 years age group (HR: $1.305,95 \%$ CI: $0.931-1.831$ ) and in the 70 years age group (HR: 1.161, 95\% CI: 0.947-1.392), there were no significant differences between sexes according to the Cox analysis. One possible explanation is that there were fewer patients in these groups than in other groups, affecting the result. However, these results also remind us that although factors other than thickness and ulceration have never been considered in previous stage IIA and T2 classifications, factors such as the Clark grade, mitotic rate, and tumour location may still affect the final survival outcome. Further analyses should be conducted in the future to clarify the specific impact of these factors on patients with stage IIA melanoma.

Although some studies have indicated that the female survival advantage was a result of biology $(15,16)$, lifestyle is also one an important factor that could lead to an advantage. Since ultraviolet (UV) exposure is a clear cause of malignant melanoma $(17,18)$, many studies have suggested that women's clothing styles and frequent usage of sunscreen may be protective factors, which explains why females are far less likely than males to develop malignant melanoma on the trunk $(19,20)$. In Australia and European countries, the mortality rates of melanoma are higher than those in East Asian countries. In addition to skin colour, people in these countries engage in sunbathing, and exposure to environmental UV light may be important factor that affects the morbidity rate and prognosis (21). Moreover, males are more likely to engage in outdoor work and sports, and they have higher rates of smoking, drinking and drug use than females, all of which may lead to a decrease in survival (19).

Our study has some limitations. First, patients in this study were all from the United States, and previous research has shown that race, nationality and even latitude can significantly impact MSS. Second, the therapeutic regimen was not included in the survival analysis, which may also affect the results. 


\section{Conclusions}

In summary, we have demonstrated that among patients in the SEER database, male melanoma patients had a lower OS rate than female patients with the same melanoma stage based on the 8 th edition of the AJCC staging system. This difference was significant in all age groups in the stage IA group but fluctuated with age in the stage IB and IIA groups. Clinicians should be aware of this difference when considering treatment, strengthen postoperative education and regularly follow patients.

\section{Acknowledgments}

Funding: This work was supported by the National Natural Science Foundation of China (81800241), Postgraduate Research \& Practice Innovation Program of Jiangsu Province (SJCX20_0484) and the Fundamental Research Funds for the Central Universities (14380479).

\section{Footnote}

Reporting Checklist: The authors have completed the STROBE reporting checklist. Available at http://dx.doi. org/10.21037/atm-20-3845

Conflicts of Interest: All authors have completed the ICMJE uniform disclosure forms (Available at http://dx.doi. org/10.21037/atm-20-3845). Dr. Mo serves as an unpaid Section Editor of Annals of Translational Medicine from Jan 2020 to Dec 2020. The other authors have no conflicts of interest to declare.

Ethics Statement: The authors are accountable for all aspects of the work in ensuring that questions related to the accuracy or integrity of any part of the work are appropriately investigated and resolved. The study was conducted in accordance with the Declaration of Helsinki (as revised in 2013).

Open Access Statement: This is an Open Access article distributed in accordance with the Creative Commons Attribution-NonCommercial-NoDerivs 4.0 International License (CC BY-NC-ND 4.0), which permits the noncommercial replication and distribution of the article with the strict proviso that no changes or edits are made and the original work is properly cited (including links to both the formal publication through the relevant DOI and the license). See: https://creativecommons.org/licenses/by-nc-nd/4.0/.

\section{References}

1. Gershenwald JE, Scolyer RA, Hess KR, et al. Melanoma staging: Evidence-based changes in the American Joint Committee on Cancer eighth edition cancer staging manual. CA Cancer J Clin 2017;67:472-92.

2. Balch CM, Buzaid AC, Soong SJ, et al. Final version of the American Joint Committee on Cancer staging system for cutaneous melanoma. J Clin Oncol 2001;19:3635-48.

3. Balch CM, Gershenwald JE, Soong SJ, et al. Final version of 2009 AJCC melanoma staging and classification. J Clin Oncol 2009;27:6199-206.

4. Evans JL, Vidri RJ, MacGillivray DC, et al. Tumor mitotic rate is an independent predictor of survival for nonmetastatic melanoma. Surgery 2018;164:589-93.

5. Haydu LE, Lo SN, McQuade JL, et al. Cumulative Incidence and Predictors of CNS Metastasis for Patients With American Joint Committee on Cancer 8th Edition Stage III Melanoma. J Clin Oncol 2020;38:1429-41.

6. Mo R, Chen C, Pan L, et al. Is the new distribution of early esophageal adenocarcinoma stages improving the prognostic prediction of the 8 (th) edition of the TNM staging system for esophageal cancer? J Thorac Dis 2018;10:5192-8.

7. Crocetti E, Fancelli L, Manneschi G, et al. Melanoma survival: sex does matter, but we do not know how. Eur J Cancer Prev 2016;25:404-9.

8. El Sharouni MA, Witkamp AJ, Sigurdsson V, et al. Sex matters: men with melanoma have a worse prognosis than women. J Eur Acad Dermatol Venereol 2019;33:2062-7.

9. Hieken TJ, Glasgow AE, Enninga EAL, et al. Sex-Based Differences in Melanoma Survival in a Contemporary Patient Cohort. J Womens Health (Larchmt) 2020;29:1160-7.

10. Khosrotehrani K, Dasgupta P, Byrom L, et al. Melanoma survival is superior in females across all tumour stages but is influenced by age. Arch Dermatol Res 2015;307:731-40.

11. Enninga EAL, Moser JC, Weaver AL, et al. Survival of cutaneous melanoma based on sex, age, and stage in the United States, 1992-2011. Cancer Med 2017;6:2203-12.

12. Pérez-Gómez B, Aragonés N, Gustavsson P, et al. Do sex and site matter? Different age distribution in melanoma of the trunk among Swedish men and women. Br J Dermatol 2008;158:766-72.

13. Kanaki T, Stang A, Gutzmer R, et al. Impact of American Joint Committee on Cancer 8th edition classification on staging and survival of patients with melanoma. Eur J Cancer 2019;119:18-29.

14. Lira FE, Podlipnik S, Potrony M, et al. Inherited MC1R 
variants in patients with melanoma are associated with better survival in women. Br J Dermatol 2020;182:138-46.

15. Joosse A, van der Ploeg AP, Haydu LE, et al. Sex differences in melanoma survival are not related to mitotic rate of the primary tumor. Ann Surg Oncol 2015;22:1598-603.

16. Utjés D, Malmstedt J, Teras J, et al. 2-cm versus 4-cm surgical excision margins for primary cutaneous melanoma thicker than $2 \mathrm{~mm}$ : long-term follow-up of a multicentre, randomised trial. Lancet 2019;394:471-7.

17. Gupta S, Artomov M, Goggins W, et al. Gender Disparity and Mutation Burden in Metastatic Melanoma. J Natl Cancer Inst 2015;107:djv221.

18. Che G, Huang B, Xie Z, et al. Trends in incidence and

Cite this article as: Mo R, Chen C, Jiang Y, Ma Z, Meng X, Tan Q. Sex-specific survival benefit in early skin melanoma based on 8th AJCC edition: an analysis of data from the Surveillance, Epidemiology, and End Results (SEER) database. Ann Transl Med 2021;9(1):53. doi: 10.21037/atm-20-3845 survival in patients with melanoma, 1974-2013. Am J Cancer Res 2019;9:1396-414.

19. Yang DD, Salciccioli JD, Marshall DC, et al. Trends in malignant melanoma mortality in 31 countries from 1985 to 2015. Br J Dermatol 2020;183:1056-64.

20. Gamba CS, Clarke CA, Keegan TH, et al. Melanoma survival disadvantage in young, non-Hispanic white males compared with females. JAMA Dermatol 2013;149:912-20.

21. Gutiérrez-González E, López-Abente G, Aragonés N, et al. Trends in mortality from cutaneous malignant melanoma in Spain (1982-2016): sex-specific agecohort-period effects. J Eur Acad Dermatol Venereol 2019;33:1522-8. 